\title{
A EDUCAÇÃO DE JOVENS E ADULTOS POR UM OLHAR PSICOPEDAGÓGICO
}

\author{
Luzinete Martins de Assis ${ }^{1}$
}

RESUMO: Segundo a Constituição Brasileira, a educação é um direito básico e fundamental de todo e qualquer cidadão, devendo ser utilizada como instrumento de promoção da equidade social. No entanto, como muitos de nós sabemos e apesar de a educação ser oferecida de forma gratuita em toda e qualquer cidade do país, o Brasil ainda conta com índices muito altos de analfabetos e de pessoas que abandonaram os estudos sem concluir. Visando sanar este problema que atinge desde a educação básica até o ensino médio, foi criado o EJA, sigla para "Educação de Jovens e Adultos". Utilizando-se da metodologia de pesquisa bibliográfica, o presente artigo tem como objetivo a compressão de como se configurou no Brasil a Educação de Jovens e Adultos ao longo da história e refletir sobre a sua importância e práticas pedagógicas. Abordaremos primeiramente um breve relato histórico sobre a EJA no Brasil, em seguida falaremos sobre o papel da escola enquanto ser social. Outro ponto a ser abordado nesta pesquisa é o perfil dos alunos da EJA, faremos também uma breve explanação sobre o cenário atual e desafios a serem enfrentados por essa modalidade de ensino. Para finalizar analisaremos qual a contribuição que a psicopedagogia pode trazer para a Educação de Jovens e Adultos.

Palavras-chaves: Educação de Jovens e Adultos. Escola. Práticas Pedagógicas.

ABSTRACT: According to the Brazilian Constitution, education is a basic and fundamental right of every citizen, and should be used as an instrument to promote social equity. However, as many of us know and although education is offered free of charge in every city in the country, Brazil still has very high rates of illiterates and people who have dropped out without completing. In order to solve this problem that reaches from basic education to high school, the EJA, an acronym for "Youth and Adult Education" was created. Using the methodology of bibliographic research, this article aims to has established in Brazil the Education of Young and Adults throughout history and reflect on its importance and pedagogical practices. We will first discuss a brief historical account of the EJA in Brazil, and then we will talk about the role of the school as a social being. Another point to be addressed in this research is the profile of the students of the EJA, we will also make a brief explanation about the current scenario and challenges to be faced by this type of teaching. Finally, we will analyze the contribution that psychopedagogy can bring to youth and adult education.

I Pós-Graduação: Psicopedagogia. Instituto Matogrossense de Pós- graduação e Serviços EducacionaisImpactos. Área do Conhecimento: Educação.E- mail: luzinetemartinsdeassis729@gmail.com 
Keywords: Youth and Adult Education. School. Pedagogical practices.

\section{INTRODUÇÃO}

A educação escolar é um bem indispensável para o desenvolvimento do indivíduo, não somente no que diz respeito ao mercado de trabalho, mas também para seu desenvolvimento pessoal e atuação na sociedade.

No Brasil existem ainda milhões de pessoas analfabetas e um número muito grande de indivíduos que apresentam um perfil diferente das pessoas que não aprenderam a ler e escrever: eles passaram pela escola e nela não obtiveram êxito, são os chamados analfabetos funcionais. Eles leem, mas não conseguem compreender. Apresentam muitas dificuldades para lidar com situações que envolvam a leitura e a escrita. E esse fenômeno tem sido crescente no país.

Visando atender as necessidades do público não alfabetizado, o Brasil tem promovido políticas públicas de combate ao analfabetismo. Contudo, esse tema ainda tem sido bastante discutido devido à existência de grande quantidade de pessoas não alfabetizadas. Esse fator tem levado o governo e a sociedade a promoverem ações que visem o sucesso da alfabetização de jovens e adultos objetivando erradicar o analfabetismo no país.

A EJA surge com o objetivo de atender essas pessoas que não tiveram ou, não puderam frequentar a escola na idade regular por motivos que variam entre as necessidades econômicas da família, reprovação por dificuldade cognitiva, paternidade e maternidade prematura e o próprio desinteresse pelo conteúdo escolar.

Alfabetizar Jovens e Adultos é uma preocupação antiga que não se limita a uma tarefa meramente escolar, está intimamente ligada a sonhos, expectativas e anseios de mudanças.

Diante disso esse estudo tem como objetivo a compressão de como se configurou a Educação de Jovens e Adultos ao longo da história e refletir sobre a sua importância e práticas pedagógicas.

Abordaremos primeiramente um relato histórico sobre a EJA no Brasil, em seguida falaremos sobre o papel da escola enquanto ser social. Outro ponto a ser abordado nesta pesquisa é o perfil dos alunos da EJA, faremos também uma breve explanação sobre o cenário atual e desafios a serem enfrentados por essa modalidade de ensino. Para finalizar 
analisaremos qual a contribuição que a psicopedagogia pode trazer para a Educação de Jovens e Adultos.

\section{METODOLOGIA}

A metodologia utilizada para este trabalho foi a pesquisa de bibliografia, onde se coletou informações de textos, livros, artigos e demais documentos de carácter científico. O tema em questão foi analisado em diferentes ângulos por autores de diferentes pontos de vista onde pode-se chegar as observações e conclusões expostas neste documento.

\section{BREVE HISTÓRICO DA EDUCAÇÃO DE JOVENS E ADULTOS NO BRASIL}

Ao longo de sua história, a Educação de Jovens e Adultos, como é conhecida atualmente, realizou-se como prática social através de instituições formais ou não. $\mathrm{Na}$ história do Brasil é possível perceber as dificuldades encontradas nessa modalidade de ensino, desde a época em que os jesuítas eram responsáveis pela educação até os dias de hoje.

$\mathrm{Na}$ época colonial, a Companhia Missionária de Jesus tinha a função básica de catequizar e alfabetizar na língua portuguesa os indígenas que viviam na colônia brasileira durante o processo de colonização, após a chegada dos padres jesuítas, em 1549. Estes se voltaram para a catequização e instrução de adultos e adolescentes, tanto de nativos quanto de colonizadores, diferenciando apenas os objetivos para cada grupo social, através dos subprodutos das escolas de ordenação criadas pelo Padre Manoel da Nóbrega.

A Educação dada pelos jesuítas, através da catequização das nações indígenas, tinha preocupação com os ofícios necessários ao funcionamento da economia colonial, constando de trabalhos manuais, ensino agrícola e, muito raramente, leitura e escrita.

Depois que os jesuítas saíram do Brasil em 1759 expulsos em pelo marquês de Pombal, toda estrutura educacional passou por transformações. A educação ficou sob a responsabilidade do Império, e foi sendo marcada por um caráter elitista, onde somente aos filhos dos colonizadores portugueses brancos e do sexo masculino tinha acesso, a população negra, indígena e as mulheres passam a ser excluídas. (Stephanou 2005, p.ro4).

A alfabetização de jovens e adultos chegou ao final do século XIX de maneira irregular e deficiente, de acordo como o Censo Nacional de 1900 , nessa época 65,3\% da população com mais de 15 anos de idade era analfabeta. 
Em 1934, foi criado o Plano Nacional de Educação que previa o ensino primário integral obrigatório e gratuito estendido às pessoas adultas. Esse foi o primeiro plano na história da educação brasileira que previa um tratamento específico para a educação de jovens e adultos.

De acordo com Ribeiro (1997, pg. 19-20), após a ditadura em 1945 e o fim da Segunda Guerra Mundial, sobre a influência da ONU que alertava para a urgência de integrar os povos visando a paz e a democracia, a educação de jovens e adultos começou a ganhar destaque dentro da preocupação geral com a educação elementar comum.

No ano de 1947, o governo criou a Campanha Nacional de Educação de Adultos que propunha alfabetizar em três meses e com esse acontecido Paulo Freire se destacou e começou a ser referência na alfabetização de adultos.

EM dezembro de 1967, o governo então assumi o controle da alfabetização de adultos e surgi então O Movimento Brasileiro de Alfabetização - Mobral, que é extinto em I985 com o final da ditadura.

$\mathrm{Na}$ década de 70 destaca-se no país o ensino supletivo, criado em 1971 pela Lei de Diretrizes e Bases da Educação Nacional (no. 5.692/7I) (BRASIL, I97I).

No governo de José Sarney (1985 a 1990) é criado a Fundação Educar, que passou a fazer parte do Ministério da Educação, mas não exerceu ação direta no campo da alfabetização, apenas supervisionava e acompanhava o trabalho desenvolvido.

A Lei de Diretrizes e Bases da Educação Nacional (LDB) (nº.9.394/96), surgiu em I996 reafirmando o direito de todos os jovens e adultos a educação básica sendo o dever do Estado promover esta educação de forma gratuita. O que foi reforçado com a nova Constituição de 1988 que prevê que todas as pessoas tenham acesso à educação.

Em continuidade à trajetória histórica da Educação de Jovens e Adultos no Brasil, temos a criação pelo MEC do Programa Brasil Alfabetizado em 2003 e em 2007 a criação do Fundo de Desenvolvimento da Educação Básica (FUNDEB), onde os recursos financeiros destinados à educação passavam para todos as modalidades de ensino.

De acordo com as últimas informações do Ministério da Educação o governo identificou falhas nesses programas, como uma taxa média de alfabetização de 50\%, quando somente $7 \%$ dos alfabetizados continuam na EJA. O MEC vem discutindo as dificuldades do atual modelo com vários segmentos da sociedade - incluindo educadores, gestores, sociedade civil -, no sentido de corrigir as falhas e aprimorar o programa. Ao 
mesmo tempo, tem discutido, de forma mais ampla, políticas de educação voltadas para a alfabetização, com o objetivo de promover um combate efetivo ao analfabetismo.

Todos esses projetos e planos pretendiam o desenvolvimento da educação e a extinção do analfabetismo no Brasil, porém, os níveis de organização desses planos eram bastante confusos. Criava-se projetos e mais projetos e sem ter, muitas vezes, o tempo devido para dar resultado, eram desmantelados ou trocados por outros projetos. Vale ressaltar que o governo sofria muita pressão tanto internacional através de órgãos como UNESCO E ONU, quanto nacional dos movimentos populares.

\section{FUNÇÃO SOCIAL DA ESCOLA NA EDUCAÇÃO DE JOVENS E ADULTO}

Ao longo da história, a escola passou por grandes transformações, acompanhando as mudanças que ocorreram na sociedade e mesmo diante disso a função social da escola não pode, e nem deve desviar-se de seu foco principal que é a formação de indivíduos críticos e criativos que consigam realizar integralmente seu papel de cidadão, contribuindo nos processos de reforma e organização da realidade. Ter compreensão da função social da escola e do sujeito que se procura formar é imprescindível para que a atividade pedagógica

seja adequada e socialmente comprometida, assim mais nitidamente as funções do Ensino de Jovens e Adultos (EJA), apresentam para a sociedade moderna sua importância e sua necessidade de existir.

Segundo Maria Hermínia Lage Fernandes Laffin (2014, p.6I)

A escola voltada à educação de jovens e adultos é, ao mesmo tempo, um local de confronto de culturas e, como qualquer situação de interação social, um local de encontro de singularidades, fazendo-nos refletir sobre sua condição de "nãocrianças" de condição de excluídos da escola e a condição de membros de determinados grupos culturais. Não se tem muitas teorias referentes aos adultos, pois a fase adulta tem sido encarada como um período de estabilidade e ausência de mudanças, em que o adulto está inserido no mundo do trabalho e possui uma história. O problema da educação de jovens e adultos é uma questão de especificidade cultural, sendo o primeiro traço cultural, muitas vezes, condição de excluído da escola, e por isso é necessário adequar a escola para esses novos sujeitos.

No que se diz respeito a Educação de Jovens e Adultos (EJA), mediante aos documentos oficiais: Lei 9394/96 (LDB/96), Parâmetros Curriculares Nacionais (PCNs), o Plano Nacional de Educação 200I e a Constituição Federal de 1988, a função social qual a EJA se propõe a cumprir é a de preparar jovens e adultos, através de oportunidades educacionais apropriadas, consideradas as características do alunado, seus interesses, 
condições de vida e de trabalho, possibilitar aos educandos aquisição de conhecimentos e habilidades necessários ao exercício da cidadania, preparação para o mundo do trabalho e participação crítica na vida política.

Segundo Barroso:

\begin{abstract}
Atualmente, a função social da escola é residual e não está conseguindo cumprir como seu papel (...). Nesse contexto, se discute as possibilidades de estabelecer uma outra relação entre a escola e o local, pois pode dar um novo sentido e significado a essa instituição e contribuir para reinvenção de outra regulação e organização. Esse é o grande desafio que se coloca, atualmente, para combater a exclusão e a segregação interna e externados indivíduos.
\end{abstract}

O autor nos fala de reinvenção e um novo sentido para o modelo de escola atual, visto que segundo ele a escola não tem cumprido seu papel social, que é a formação do sujeito crítico, consciente de seu papel na sociedade.

\title{
PERFIL DO ALUNO DO EJA
}

Em todos as áreas e modalidades de ensino o estudo deve estar direcionado ao aluno e não o oposto. Na EJA, esta concepção deve ser ainda mais reforçada, uma vez que o jovem e o adulto que buscam esta forma de ensino já trazem consigo experiências de vida e saberes informais acumulados durante sua vida. De forma geral, os alunos que buscam a EJA para dar continuidade aos seus estudos são indivíduos de classe trabalhadora, muitos desempregados ou vivendo por meio de subempregos.

Gadotti (2002) define o perfil dos alunos da EJA da rede pública, sendo na maioria trabalhadores proletariados, desempregados, donas de casa, jovens, idosos e portadores de deficiências especiais. São alunos com suas diferenças culturais, etnias, religião e crenças. Chegam na sala de aula trazendo consigo experiências de vida e saberes informais acumulados, buscam em programas de EJA uma oportunidade para aprender e assim melhorar a sua condição de vida.

Aristimunha e Rodrigues (2004, p. 38I) resumem os alunos de EJA citando que:

Geralmente, são pessoas que ou nunca estiveram na Escola ou tiveram que abandoná-la por diversos motivos [...]. Quase sempre procuram começar/retomar os estudos, na modalidade EJA com alguns desejos/demandas sejam eles: assinar o nome; ler placas de ônibus, o jornal, a Bíblia, bulas de remédios, etc.; escrever cartas/bilhetes; fazer contas; falar "direito"; conseguir emprego; ascender profissionalmente/fazer concurso. Como podemos ver, na sua grande maioria, 
ligados ao fazer cotidiano e ao Mundo do Trabalho. (ARISTIMUNHA e RODRIGUES, 2004, p. 38r).

Esses alunos buscam a escola com a intenção de conseguir melhores empregos, e veem na EJA uma oportunidade para isso. Em grande parte, são discriminados na escola por trazerem uma história de entradas e saídas em cursos anteriores, por motivos que variam entre cansaço depois de um longo dia de trabalho, desestimulo por parte da família, alimentação deficiente e até mesmo por questão educacionais, como recursos e metodologias inadequadas.

Santos diz:

\begin{abstract}
Os jovens e adultos pouco escolarizados trazem consigo um sentimento de inferioridade, marcas de fracasso escolar, como resultado de reprovações, do não aprender. A não-aprendizagem, em muitos casos, decorreu de um ato de violência, porque o aluno não atendeu às expectativas da escola. Muitos foram excluídos da escola pela evasão (outro reflexo do poder da escola, do poder social); outros a deixaram em razão do trabalho infantil precoce, na luta pela sobrevivência (também vítimas do poder econômico) (SANTOS, 2003, p. 7).
\end{abstract}

\title{
METODOLOGIA DE ENSINO NA EJA
}

Nos deparamos então com a pergunta: Como ensinar? Apesar de o currículo ser essencialmente o mesmo da educação regular, quem frequenta a EJA já é adulto e busca outra finalidade com os estudos.

Ao escolher a metodologia de ensino o professor precisa estar atento ao contexto social, cultural, político, e econômico e, as necessidades educativas dos alunos de modo que esta favoreça a aprendizagem. A atividade docente requer organização e planejamento, de modo que a metodologia utilizada pelo professor facilite o processo de ensinoaprendizagem, fazendo aplicações em cada disciplina com as problemáticas reais do dia a dia, tornando-o um processo prazeroso, mas sobre tudo eficaz. Os alunos da EJA necessitam de conteúdos de aplicação prática para a vida diária e para resolução de problemas.

De acordo com Gadotti, 1996 p.83:

[...] na própria realidade dos educandos, o educador conseguirá promover a motivação necessária à aprendizagem, despertando neles interesses e entusiasmos, abrindo-lhes um maior campo para os que estão aprendendo e, ao mesmo tempo, precisam ser estimulados para resgatar sua autoestima, pois a sua ignorância lhes trará ansiedade, angustia e complexo de inferioridade. Esses jovens e adultos são tão capazes como uma criança, exigindo somente mais técnica e metodologia eficientes para esse tipo de modalidade. 
De acordo com Soares (2005), as discussões sobre a EJA têm priorizado as seguintes temáticas:

\begin{abstract}
A necessidade de se estabelecer um perfil mais aprofundado do aluno; a tomada da realidade em que está inserido como ponto de partida de ações pedagógicas; o repensar de currículos, com metodologias e materiais didáticos adequados às suas necessidades; e, finalmente, a formação de professores que condizem com a sua especificidade (SOARES 2005, p. 202).
\end{abstract}

De acordo com a proposta dos Parâmetros Curriculares Nacionais a Educação de Jovens e Adultos deve ser pensada como um modelo pedagógico próprio, como objetivo de criar situações de ensino-aprendizagem adequadas às necessidades educacionais de jovens e adultos, englobando as três funções: a reparadora, a equalizadora e a permanente, citadas no PareceriI/oodaCEB/CNE.

- Reparadora: Pois restitui um direito negado - direito a uma educação de qualidade que é garantido por lei;

- Equalizadora: Porque dá cobertura a trabalhadores e vários outros segmentos sociais (dona de casa, aposentados, migrantes) para reentrada no sistema educacional;

- Permanente: Propicia a todos a atualização de conhecimento por toda a vida, dando ferramentas para o exercício da cidadania;

A Proposta Curricular em Educação Para Jovens e Adultos do Ministério da Educação, ressalta que quem trabalha neste segmento deve conhecer os alunos "suas expectativas, sua cultura, as características e problemas de seu entorno e suas necessidades de aprendizagem".

A maioria dos jovens e adultos que retornam a escola apresentam uma autoestima muito baixa, acham que não são capazes de aprender, se sentem desvalorizados e excluídos, são marcados pelas várias experiências frustrantes que passam durante sua trajetória de vida tanto do lado de fora da escola quanto as vividas dentro das instituições. A escola, precisa resgatar a autoestima desse aluno, valorizar seus saberes e experiências, mas do que trazer esses alunos para dentro das salas de aula é preciso investir na permanência deles ali.

Sobre a metodologia de ensino na EJA Maria Hermínia Lage Fernandes Laffin (2014, P.74) salienta:

Entendemos que a EJA deve ser considerada um espaço de relacionamento, de diálogo entre saberes, de compreensão e de reconhecimento da experiência e da sabedoria. Conciliar o espaço do saber com o espaço das relações sociais é uma ação transformadora na vida do sujeito da EJA. 
Outro ponto a ser observado é o processo de avaliação, é preciso que o professor do EJA reflita sobre suas práticas de forma que essas favoreçam o processo de aprendizagem dos educandos.

O meio de avaliação na EJA igualmente como em qualquer outra categoria de ensino, é uma fase fundamental na didática do docente, isto porque este é um momento de compreendê-la como um processo constante e sistemático a fim de que se consiga observar o crescimento do educando ao longo da sua trajetória, e consequentemente, fazer as devidas adequações quando necessárias, no intuito de que sejam alcançados os objetivos indicados para o ensino e a aprendizagem.

Ribeiro (1997, p. 2260) retrata a importância dos alunos da Educação de Jovens e Adultos participarem de uma avaliação contínua de suas aprendizagens, visando a aquisição de maior consciência e controle acerca de seus conhecimentos e de suas próprias atividades.

Segundo Haydt (1997, p.I4), "atualmente, a avaliação assume novas funções, pois é um meio de diagnosticar e de verificar em que medida os objetivos propostos para o processo ensino aprendizagem estão sendo atingidos".

Sendo assim, uma avaliação diagnóstica, sistemática e permanente, com utilização de instrumentos diversificados, voltada para as necessidades e considerando o perfil de cada educando e a função social da EJA, é o tipo de avaliação ideal.

\section{EJA DESAFIOS E POSSIBILIDADES}

O Brasil já deu um grande passo nas questões que se referem a alfabetização de jovens e adultos, embora continuamos dentro da escala dos países com maior taxa de analfabetos. Infelizmente o Brasil ainda tem II,8 milhões de analfabetos, segundo o Instituto Brasileiro de Geografia e Estatística (IBGE), um número muito alto de pessoas ainda não se apropriaram da cultura escrita.

De acordo com dados do IBGE e do Ministério da Educação (MEC), em 2015, havia quase 3,5 milhões de matriculados na EJA, sendo 2.182.6II no Ensino Fundamental e I.309.258 no Ensino Médio. Embora os números pareçam altos, desde 2007 o total de matrículas de EJA já caiu aproximadamente 1,5 milhão, com a maior queda na faixa de 30 a 59 anos, hoje com 680 mil alunos a menos. 
O que se tem observado na realidade é que a função do EJA está sem cumprida de forma paliativa, na maior parte do tempo envolve somente ações de alfabetização do educando, ao contrário do que determina o PNE 20oI, que faz direção não só a alfabetização, mas também aos aspectos de desenvolvimento integral do educando enquanto cidadão:

Apesar dos esforços do Governo Federal, os investimentos na educação precisam ser melhorados. Para combater o analfabetismo, é necessário que tanto o Governo Federal como estados e municípios priorizem o investimento na EJA.

Entre muitos problemas enfrentados pela EJA, encontra-se também a precária formação do professor. Muitos professores vão atuar nessa modalidade de ensino, totalmente despreparados, especialmente por não conhecer as especificidades da EJA e por não ter recebido uma formação consistente que o preparasse para trabalhar com educandos jovens e adultos.

Outro fator a ser observado é a questão da evasão escolar na Educação de Jovens e Adultos, os altos índices de abandono dos alunos chamam a atenção e impressionam com frequência, pois, em muitas salas da EJA, o número de alunos evadidos a cada semestre chega a ser superior ao número de alunos aprovados e tem servido como pretexto para o fechamento de muitas classes.

Os motivos pelos quais esses alunos abandonam as salas de aulas são bastante diversos, dentre eles, desestruturação familiar, desemprego, incompatibilidade de horários, dificuldade em se adaptar com o professor ou com a metodologia utilizada, material didático inadequado e ainda algumas vezes por não considerarem significativa os ensinos que estão recebendo.

A alfabetização dessas pessoas deve acontecer de uma forma ampla para que elas tenham o domínio dos principais meios da cultura letrada, das operações matemáticas principais, do movimento histórico, das relações humanas, da pluralidade do espaço físico e político mundial e da organização da sociedade brasileira. Implica ainda a formação do cidadão consciente e responsável de seus direitos e deveres.

Há uma necessidade de sensibilização sobre a função primordial da educação, pensar em infraestrutura, pois o espaço físico é um insumo necessário. Também é preciso ver a questão dos horários, porque a maioria trabalha, e pensar numa carga horária adaptada a essa realidade. É necessário agregar esforços com os poderes públicos, uma 
corresponsabilidade, para se efetivar tal oferta e essa tarefa é de todos: gestores públicos e escolares, professores, estudantes, empresas, universidades e demais instituições sociais e comunidade.

Os desafios encontrados para a garantia do direito dos jovens e adultos à Educação são complexos, mas muitos podem e devem ser enfrentados, pelas equipes escolares, pela mobilização da comunidade, pelos professores, a fim de tornar a EJA um ambiente acolhedor da diversidade e a flexibilização dos modelos de atendimento.

\section{CONTRIBUIÇÕES DA PSICOPEDAGOGIA NA EDUCAÇÃO DE JOVENS E ADULTOS}

Até o momento foram apresentados muitas das situações adversas em que a Educação de Jovens e Adultos está inserida, a partir de agora procuraremos analisar como a psicopedagogia pode contribuir para a melhoria das práticas pedagógicas nesta modalidade de ensino, de modo que a aprendizagem aconteça de forma integral, ou seja, nos aspectos afetivo, cognitivo, social, corporal e de outras maneiras necessárias.

De acordo com o Código de Ética dos Psicopedagogos, “a Psicopedagogia é um campo de atuação em Saúde e Educação que lida com o processo de aprendizagem humana; seus padrões normais e patológicos, considerando a influência do meio - família, escola e sociedade - no seu desenvolvimento, utilizando procedimentos próprios da psicopedagogia" (Artigo I으).

O psicopedagogo busca entender a maneira como o ser humano assimila e processa as informações, construindo, assim, os conhecimentos. Ele é responsável, portanto, pelo estudo dos processos do aprender humano em várias fases da vida, seja em crianças e adolescentes ou em adultos.

As dificuldades na aprendizagem dos alunos na EJA merecem investigação, pois podem ocorrer pela metodologia utilizada, disparidade de contextos, idades distintas, desejos e objetivos não correlacionados, imaturidade, despreparo dos professores que atuam nessa modalidade de ensino, horários impróprios quando envolvem trabalhadores. "A identificação das causas dos problemas de aprendizagem escolar requer uma intervenção especializada".

(BOSSA, 2000, p.12). 
Diante de um problema, o psicopedagogo é capaz através seus conhecimentos e técnicas melhorar a capacidade do aluno de compreender os ensinamentos transmitidos pelos professores e o ajudar a conhecer as próprias deficiências, que o impedem de acompanhar os colegas. Além de atuar na identificação desses problemas, o psicopedagogo busca soluções para situações como evasão escolar e distúrbios comportamentais dos estudantes.

De acordo com Escott:

O fracasso escolar está alicerçado basicamente, sobre duas dimensões que se influenciam numa relação dialética: a individual, que diz respeito ao aluno e suas vivências, pertencentes a uma estrutura familiar, e outra externa, que corresponde à escola e aos seus aspectos culturais, ideológicos e sociais da aprendizagem. (Escott, 2004, p.37).

O psicopedagogo pode atuar também de forma preventiva, ou seja, exercer a ação antes que os problemas de aprendizagem apareçam de fato. Ele pode trabalhar na preparação dos profissionais da educação, orientar sobre a metodologia mais adequada de acordo com as peculiaridades dos alunos, proporcionar meios para desenvolver a inclusão, realizar processo de orientação educacional, vocacional e ocupacional, tanto na forma individual quanto em grupo.

Sobre a atuação do psicopedagogo no contexto escolar Fagali diz:

A orientação do psicopedagogo junto ao professor deve ser constante, discutindo não apenas as relações vinculares, mas também as que dizem respeito ao conteúdo, atuação do aluno, formas de avaliação e reação dos pais frente a essa nova postura da instituição. Desta forma o professor poderá rever constantemente a relação afetiva e as dificuldades do educando e saber esperar pela resposta e produção do aluno, independente das pressões e tensões. Trabalhar a ansiedade do aluno, dos pais, da escola e dele próprio enquanto educador. Todos os níveis da administração escolar devem estar comprometidos com o processo e devidamente orientados para o sucesso do projeto psicopedagógico dos conteúdos. (FAGALI, 2009, p.I4-15).

Desta forma, torna-se fundamental o papel do Psicopedagogo no âmbito escolar: prevenir os entraves que permeiam o fracasso e quando este já ocorrido, desenvolver subsídios motivadores a fim de superá-los.

A escola, enquanto instituição possui sua função de promover as condições necessárias para proporcionar a aprendizagem e o desenvolvimento do sujeito que busca a educação, seja ele crianças, jovens, adultos ou idosos. O professor está ali como um mediador do saber e os alunos e por ser aquele está mais próximo do aluno tem condições de pontuar as situações que estejam atrapalhando o desenvolvimento integral do aluno, 
porém o psicopedagogo é o profissional habilitado para atuar no processo de aprendizagem, fazer o diagnóstico e promover interversões nos casos de Dificuldades de Aprendizagem.

\section{CONSIDERAÇÕES FINAIS}

Após a realização desta pesquisa, entendemos que o fato da Educação de Jovens e Adultos hoje ser reconhecida como uma modalidade de ensino já é uma vitória, mas que ainda está muito longe de ser o ideal.

Entendemos que a Educação de Jovens e Adultos é um direito muito importante e de grande valia que permite aos cidadãos uma interação nos aspectos mais básicos da vida social como: ler livros, escolher seu pedido em um cardápio, escrever uma carta, pegar um ônibus, ler uma receita, escrever o próprio nome, coisas simples, mas que, sem dúvida, faz toda a diferença na vida de qualquer indivíduo.

O ideal seria que o Brasil se comprometesse com uma escola pública que não excluísse ninguém, que todos tivessem condições de frequentar a escola no tempo correto, é isso envolve muitas coisas que vão além das quatro paredes das escolas, já que um dos principais motivos que as pessoas deixam de estudar estão relacionadas as condições básicas para a sobrevivência humana, a grande maioria para de estudar para trabalhar para ter o que comer.

O analfabetismo é um problema real e atual, é precisa ser levado a sério, e isso exige um comprometimento de todos.

O Estado que assuma o seu papel e cumpra o que está na lei. No artigo $205 \mathrm{da}$ Constituição Federal de 1988 diz que: " A educação, direito de todos e dever do Estado e da família, será promovida e incentivada com a colaboração da sociedade, visando ao pleno desenvolvimento da pessoa, seu preparo para o exercício da cidadania e sua qualificação para o trabalho". Como fazer isso cadê a ela analisar e decidir.

A escola precisa estar aberta a todas as mudanças que vem ocorrendo no decorrer dos anos, buscando sempre se adequar de acordo com as necessidades do aluno e se tratando da EJA, o professor precisa ter uma atenção especial, tendo em vista a formação integral desse aluno, levando em conta as suas especificidades e limitações.

E enquanto ao aluno do EJA que tenha em mente que ele é protagonista de sua aprendizagem, que abandone todas as frustrações, sentimentos de incapacidade e que entenda que sempre é tempo para recomeçar e fazer algo novo. 
Escola, alunos e professores possuem um aliado para enfrentar esta batalha que é o psicopedagogo. Seu papel é de extrema importância para uma nova forma de pensar, sentir e agir frente aos conteúdos e no sentido de auxiliar nos processos de ensino-aprendizagem dos alunos, de suas dificuldades e facilidades que, articulados no conjunto, configuram a identidade da comunidade escolar.

Enfim, consideramos que escola, família, comunidade, sociedade, bem como o Poder Público são corresponsáveis pela formação educacional de jovens e adultos. Desta maneira necessita-se buscar todos os meios e todas as ferramentas possíveis, afim, de sanar esse problema e garantir a todos o princípio da igualdade.

\section{REFERÊNCIAS}

ARISTIMUNHA, C. P.; RODRIGUES, C. L. Educação de Jovens e Adultos: algumas Questões. In: VII Seminário Intermunicipal de Pesquisa, 2004, Guaíba. Anais do VII Seminário Intermunicipal de Pesquisa/V Salão de Iniciação Científica/ II Mostra de Atividade Extensionistas. Canoas: Editora da ULBRA, 2004. v. or. p. 377-388.

BARROSO, João. A função social da escola. Disponível em $\frac{2304}{2}$ 〈http://www.apagina.pt/arquivo/FichaDeAutor.asp? ID=388. $>$ Acesso em i8 de maio de 2019.

BOSSA, Nádia. A psicopedagogia no Brasil: contribuições a partir da prática. Porto Alegre: Artes Médicas, 2000.

BRASIL. Constituição (1988). Constituição da República Federativa do Brasil. Brasília, DF: Senado Federal, 1988.

BRASIL, Lei n.5692. Diretrizes e Bases da Educação Nacional, 1996.

BRASIL. Ministério da Educação e do Desporto. Diretrizes Curriculares para Educação de Jovens e Adultos. Brasília, DF, 2000 
ESCOTT, Clarice Monteiro. Interfaces entre a psicopedagogia clínica e institucional: um olhar e uma escuta na ação preventiva das dificuldades de aprendizagem. Novo Hamburgo: Feevale, 2004.

FAGALI, E; VALE, Z. Psicopedagogia Institucional Aplicada: a aprendizagem escolar dinâmica e construção na sala de aula. ıo ed. Petrópolis: Vozes, 2009.

FERNANDES, P. P. (2004). Literacia Emergente. In J. Lopes, Velásquez, P. P. Fernandez, \& Bártolo. Aprendizagem, ensino e dificuldades da leitura. Coimbra: Quarteto.

FREIRE, Paulo. Pedagogia da autonomia: Saberes necessários a prática educativa. São Paulo, Ed. Paz e Terra: 1996.

GADOTTI, Moacir. Boniteza de um sonho: Ensinar e aprender com sentido. São Paulo: Cortez, 2002.

LAFFIN, Maria Hermínia Lage Fernandes (organizadora). Educação de jovens, adultos idosos na diversidade: processos de intervenção na realidade escolar e social. Florianópolis/SC: Apoio, 2014.

RIBEIRO, M. V. M (coord.) Educação de Jovens e Adultos: proposta curricular para o I segmento do ensino fundamental. São Paulo: Ação Educativa; Brasília: Mec,1997. Disponível em: 〈http://portal.mec.gov.br/secad/arquivos/pdf/eja/propostacurricular/primeirosegmento/ propostacurricular.pdf $>$. Acesso em: 4 de maio 2019.

STEPHANOU, Maria; BASTOS, Maria Helena (orgs). Histórias e Memórias da Educação no Brasil. Vol. III. Petrópolis: Vozes, 2005. 